\title{
Practical comments on recurrent laryngeal nerve neuromonitoring during thyroid surgery
}

\author{
Wioletta Masiak-Segit, Andrzej Dąbrowski, Krystyna Abramowicz, Tomasz Jerzy Jaworski, \\ Grzegorz Wallner \\ $2^{\text {nd }}$ Clinic of General and Gastrointestinal Surgery and Surgical Oncology of the Alimentary Tract, \\ Medical University of Lublin
}

Kardiochirurgia i Torakochirurgia Polska 2013; 10 (4): 374-379

\begin{abstract}
Neuromonitoring (intraoperative neurophysiological monitoring - IONM) is a new non-invasive technique, which does not place any additional strain on the patient. The surgeon uses a stimulation probe to search for the recurrent laryngeal nerve within the surgical site. IONM provides auditory and visual cues when the probe is in the vicinity of the nerve. During the stimulation of the nerve, vocal muscles are stimulated as well, which causes the vocal cords to tighten to the rhythm of the electric pulses fed to the recording electrode attached to the endotracheal tube. Neuromonitoring requires close cooperation between the surgeon and the anesthesiologist. IONM cannot serve as a substitute for technical skills and thorough knowledge of neck anatomy. Its use significantly improves patient safety and the comfort of the surgeon. Based on the literature and their own experience, the authors of the article describe the standards of the neuromonitoring procedure, the problems that may occur during its use, as well as solutions for these problems.

Key words: neuromonitoring, recurrent laryngeal nerve, thyroid surgery
\end{abstract}

In Poland, approximately 22 thousand thyroid operations are performed each year [1]. Due to the significant anatomical differences in the path of the recurrent laryngeal nerve (RLN), the percentage of complications related to its incorrect identification during surgery reaches 1-10\% [1]. The complications associated with RLN damage not only result in significant discomfort for the patient, but, in certain cases, prevent the patient from returning to previous professional activity. The risk of complications may be reduced with the use of neuromonitoring equipment during surgery.

The IONM technique constitutes a multistep medical process. The use of this technique requires good knowl-

\section{Streszczenie}

Neuromonitoring (intraoperative neurophysiological monitoring - IONM) jest nową nieinwazyjną techniką, niestanowiącą dodatkowego obciążenia dla pacjenta. Chirurg za pomocą sondy stymulacyjnej poszukuje w polu operacyjnym nerwu krtaniowego wstecznego. W momencie gdy sonda znajduje się w pobliżu nerwu, system IONM powiadamia o tym sygnałem dźwiękowym i wizualnym. W trakcie stymulacji nerwu pobudzane są mięśnie głosowe, a w rezultacie struny głosowe zaciskają się w rytm podawanych impulsów prądowych na elektrodzie odbiorczej naklejonej na rurkę intubacyjną pacjenta. Neuromonitoring wymaga ścisłej współpracy chirurga z anestezjologiem. System IONM nie zastąpi jednak umiejętności technicznych i gruntownej znajomości warunków anatomicznych szyi. Jego zastosowanie w znaczny sposób poprawia bezpieczeństwo pacjenta i komfort pracy chirurga. Autorzy pracy, na podstawie literatury i własnych doświadczeń, opisali standardy postępowania obowiązujące w neuromonitoringu oraz problemy praktyczne, które mogą wystąpić w trakcie jego stosowania, i sposoby ich rozwiązywania.

Słowa kluczowe: neuromonitoring, nerw krtaniowy wsteczny, chirurgia tarczycy.

edge of anatomical factors, basic expertise concerning electrophysiology and the necessary equipment, as well as the ability to follow the standards of RLN neuromonitoring, including the procedures used in cases of the so-called loss of signal (LOS). The standard procedures for IONM were published in the "Laryngoscope" journal in 2011 [2]. They were created by the International Neural Monitoring Study Group (INMSG) - a group consisting of specialists from various areas: surgeons, laryngologists, anesthesiologists, and electromyography (EMG) specialists. Taking into consideration the significant variety with regard to equipment and the neuromonitoring process, the proposed standards are 
aimed at unifying the procedure and, therefore, improving its quality [2]. They focus on two issues: equipment standards, mainly the placement of the endotracheal tube with a recording electrode applied onto it, and the algorithm for solving intraoperative problems when working with neuromonitoring, with special attention to the procedures used in the case of loss of signal [2]. According to the INMSG, neuromonitoring-assisted operations should be performed routinely as the so-called "difficult cases" cannot be predicted preoperatively [2]. The current procedure does not include the implementation of neuromonitoring during surgery that is already in progress. Therefore, even if the use of IONM is more beneficial in the so-called "difficult cases", using it routinely may help acquire additional experience in correct signal interpretation and curve analysis [3]. It is also important to emphasize that the literature does not feature any reports of RLN and/or vagus nerve damage resulting from stimulation [4]. The activation of the vagus nerve does not cause bradycardia or bronchospasms [5]. However, it is important to remember that, according to Drall, it would be necessary to analyze 9 million thyroidectomies performed due to nodular goiter or 40 thousand operations conducted because of thyroid cancer in order to confirm the statistically lower number of cases of recurrent laryngeal nerve paralysis achieved thanks to neuromonitoring [6].

The elements necessary for ensuring optimal IONM (according to the INMSG) are presented in Table I. Preoperative laryngoscopy should be performed in all patients qualified for thyroid surgery [2]. Evaluation based on the symptoms reported by the patient is not reliable because of the possibility of compensation by the contralateral vocal fold [2]. Preoperative paralysis of vocal folds may be a result of neoplastic infiltration or previous operation in the neck area, or a symptom of a benign disease [5]. According to Randolph et al., the total percentage of cases of preoperative vocal fold paralysis in patients who had not previously undergone surgery was 4\% [5]. Moreover, $50-60 \%$ of patients with preoperative vocal fold paralysis may be asymptomatic, which may be associated with progressive neoplastic infiltration of the nerve and a simultaneous tendency of the contralateral fold to compensate [5]. Preoperative diagnosis of vocal fold paralysis is an indication for more detailed medical imaging; it helps the surgeon plan the operation, which may also involve the trachea and larynx, and provides the patient with more accurate preoperative information concerning their condition and the potential consequences of surgical treatment [5].

The dissection and stimulation of the vagus nerve before the resection of a given lobe of the thyroid gland helps ensure the proper functioning of the IONM system and, therefore, the correct mapping of the recurrent laryngeal nerve path later on [2].

Vagus nerve stimulation after lobe resection provides the most credible prognosis of postoperative glottic function. This enables a comprehensive assessment of the neuromuscular reflex and prevents the occurrence of false negatives caused by stimulating the recurrent laryngeal nerve distally from the site of injury [2].
Postoperative laryngoscopy is necessary in all patients because there are differences with regard to the symptoms that they report and the actual functioning of the glottis $[2,5] .20-30 \%$ of patients with vocal fold paralysis after strumectomy have normal voice [5]. There is a group of patients who report postoperative voice changes; detailed examinations of voice and larynx reveal abnormal vocal fold functioning parameters in these patients, without the occurrence of vocal fold paralysis [7].

Three models of IONM use can be distinguished:

- RLN identification (mapping). The nerve is located in the paratracheal area by means of stimulation and visual identification [2].

- Aid in dissection - once the nerve is identified. Additional interrupted stimulation of the tissue surrounding the nerve and of the nerve itself may be helpful in locating the path of the nerve and its branches within the dissected site [2].

- Postoperative prognosis concerning nerve function and identification of the injury site. This use of IONM is very important in preventing bilateral vocal cord paralysis. Before the era of neuromonitoring, there was no method for identifying the site of nerve injury [2].

The majority of problems with IONM result from the incorrect positioning of the endotracheal tube [2]. Special focus on the correct positioning of the endotracheal tube during surgery is recommended, as it eliminates the majority of problems associated with intraoperative neuromonitoring. It is necessary to verify the position of the tube after the intubation of the patient, after positioning the patient with the head tilted backwards, directly after the onset of the procedure, and in the case of intraoperative problems with acquiring the signal.

The primary factor for the correct reading of nerve stimulation response is the lack of laxity in the patient's skeletal striated muscles. Intubation should, therefore, be performed after the use of short-acting non-depolarizing muscle relaxants (e.g. Scoline). A tube of the largest safe size should be chosen. This ensures good recording electrode adhesion to the vocal cords [2]. Saliva, which may accumulate at the level of the vocal cords, may result in signal disturbances. In such cases, it is helpful to use cholinolytic agents or a suction pump [2]. Right-handed anesthesiologists may exhibit a tendency to rotate the tube clockwise (sometimes even by $30^{\circ}$ ). This rotation error may be eliminated by rotating the tube in the other direction (counterclockwise). Marking the "12 o'clock" position with a marker

Tab. I.

Elements necessary for ensuring optimal IONM according to INMSG

Preoperative laryngoscopy

Dissection and stimulation of the vagus nerve before the resection of a given lobe of the thyroid gland

Stimulation of the vagus nerve after the resection of a given lobe

Postoperative laryngoscopy 
on the available edge of the electrode may help prevent tube rotation during intubation. The rotation degree of the endotracheal tube in its long axis and the depth at which it is located should become new parameters for anesthesiologists to monitor [2]. After intubation, the patient is positioned with the head tilted backwards by the surgeon. The process of positioning the patient should take place under the supervision of anesthesiology staff, responsible for the introduction of the endotracheal tube. It is necessary to remember that once the patient is repositioned, the tube may be displaced and/or rotated despite its correct initial position [2]. The verification of the positioning of the tube after tilting the patient's head backwards should become a standard procedure. Lu et al. suggest that maintaining a high level of diligence at this stage helps prevent later intraoperative problems in many cases [8].

The position on the endotracheal tube can be verified in two ways: through observation of the so-called respiratory variations or by performing intraoperative laryngoscopy. After intubation and the induction of muscle relaxation, there is a period during which the agents used for this purpose start wearing off. If the patient is not deeply sedated, they may start moving uncontrollably. At that time, before the anesthesiologist administers, for example, propofol, or before inhaled anesthetics take full effect, the IONM monitor displays the so-called "respiratory variations" - waves with the amplitude of 30-70 $\mu \mathrm{V}[2,5]$. If the variations are visible on both channels, the electrodes are at the level of the vocal cords $[2,5]$. Immediately after the respiratory variations appear on the monitor, the anesthesiologist should administer sedatives to the patient [2]. This method of verifying the position of the endotracheal tube does not require the use of any additional equipment, which is its main advantage [2].

The anesthesiologist or surgeon may examine the glottis once more by means of laryngoscopy or fiberoptic examination after properly positioning the patient. There are two new video-laryngoscopes available on the market which can be used for examination in this position.

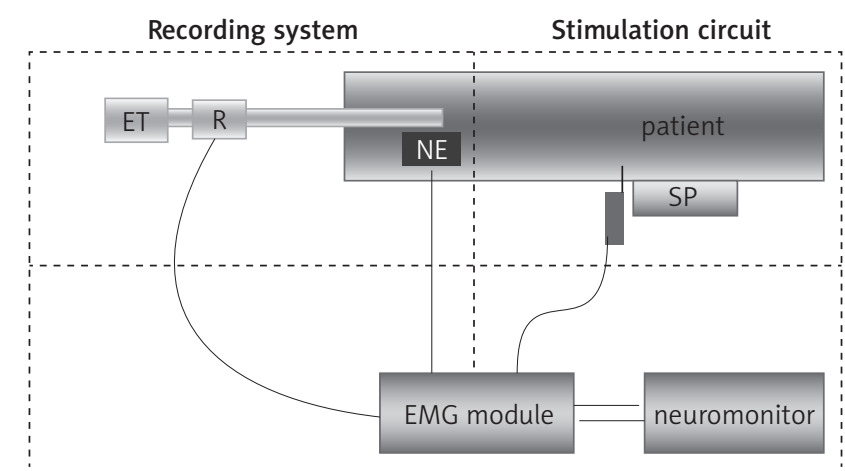

ET - endotracheal tube; RE - recording electrode (self-adhesive electrode on the endotracheal tube together with a connecting cable); NE - neutral electrode (attached to the patient's cheek); SP - stimulation probe (hand-held neurostimulator)

Fig. 1. EMG monitor scheme. Based on [2]
The position of the endotracheal tube can also be verified directly after the beginning of a surgical procedure by using one of two methods. The first method is translaryngeal stimulation [9]. It should be used directly on the thyroid cartilage or thyrohyoid membrane. It is very important to use a sufficiently strong stimulation current, so that the electrical impulse may pass through the larynx in an optimal manner [9]. If the maximum stimulation current is achieved at the level of the cricothyroid ligament, the arch of the cricoid cartilage, or below, it should be assumed that the endotracheal tube is located too deep [9]. Another method for establishing the correct position of the endotracheal tube after the onset of surgery consists in stimulating the vagus nerve directly. Satisfactory activation of the vagus nerve (as reflected by optimal EMG readings) proves correct endotracheal tube placement [2]. Verifying endotracheal tube positioning directly after the onset of surgery is equally important from the practical standpoint. If the endotracheal tube needs to be repositioned, it is usually easier to do this before surgery than during its course [2].

Before making the final assumption that a given tissue does not respond to stimulation, i.e. the achieved result is truly negative, it is necessary to make sure that the stimulation system is working correctly (Fig. 1). Achieving vagus nerve activation without any concurrent effect of recurrent laryngeal nerve stimulation points to actual loss of signal. The INMSG emphasizes that vagus nerve stimulation should be the first and the last activity during thyroidectomy (Fig. 2).

If the recurrent laryngeal nerve is being stimulated and EMG activity is not present or has an unusually low ampli-

\section{Endotracheal tube \\ - Intubation - short-acting muscle relaxants, antisialagogues (drying agents) \\ - Electrodes and vocal cords - depth of endotracheal tube insertion, make sure that it was not rotated and that saliva is not accumulating at the level of the larynx \\ - Patient position with the head tilted backwards \\ - Verifying correct endotracheal tube placement - "respiratory variation" monitoring and/or direct laryngoscopy/fiberoptic examination \\ - Fixing the endotracheal tube in a correct position \\ $\checkmark$

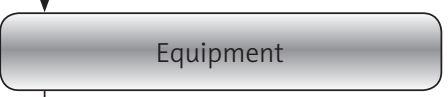 \\ - Neutral electrodes \\ - Monitor: \\ - stimulation voltage \\ - stimulation current 1-2 mA \\ - impedance (resistance) $<5 \mathrm{k} \Omega$ /electrode \\ - Spatial separation between diathermy devices and the EMG monitor

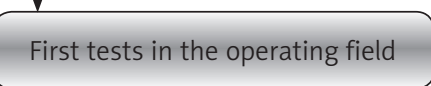 \\ - Laryngeal twitch assessment or contralateral vagus nerve stimulation}

Fig. 2. Standards of conduct with regard to EMG equipment. Based on [2] 
tude (below $100 \mu \mathrm{V}$ ), the first step of the surgeon should be to assess laryngeal twitch (Fig. 3) [5]. It is performed by inserting a finger behind the posterior end of the thyroid cartilage and stimulating the vagus nerve afterwards. If vibrations of the posterior cricoarytenoid muscles are present, it is possible to assume that laryngeal twitch occurs, and the stimulation system on the examined side is working correctly. In such cases, it is necessary to look for the source of dysfunction on the recording side (Fig. 3). In the vast majority of cases, lack of signal is caused by incorrect endotracheal tube positioning. It is also recommended to verify the positioning of the neutral electrode, which may detach or dislocate if the patient perspires [2]. Alternatively, if RLN stimulation does not result in an adequate response in the form of a characteristic EMG signal, it is possible to dissect the contralateral vagus nerve, especially if bilateral thyroidectomy is planned (Fig. 3). If there is no response to the stimulation of the contralateral vagus nerve, the cause of the lack of signal should probably be searched for on the recording side (Fig. 3). If contralateral vagus nerve stimulation does provide a satisfactory EMG signal, the problem is caused by the stimulation system, which may suggest recurrent laryngeal nerve damage (Fig. 3). It is important to remember that endotracheal tube rotation may result in divergent stimulation parameters on the two channels. The necessity of bilateral dissection may constitute a disadvantage of neuromonitoring in the case of unilateral surgery [2].

The most common problem on the recording side is the incorrect position of the endotracheal tube in relation to the vocal cords, its improper depth, or rotation in the long axis [2]. If the patient has moved or if the larynx, trachea, or thyroid has been significantly manipulated, the initially correct endotracheal tube position may be changed. This may take place during large substernal goiter surgery [2]. The correction of endotracheal tube placement may be performed by the anesthesiologist based on the initial correct endotracheal tube position recorded directly after intubation, or it can be done through direct visualization of the glottis by means of fiberoptic examination or direct laryngoscopy. After the correction of endotracheal tube placement, the surgeon should confirm that the new posi-

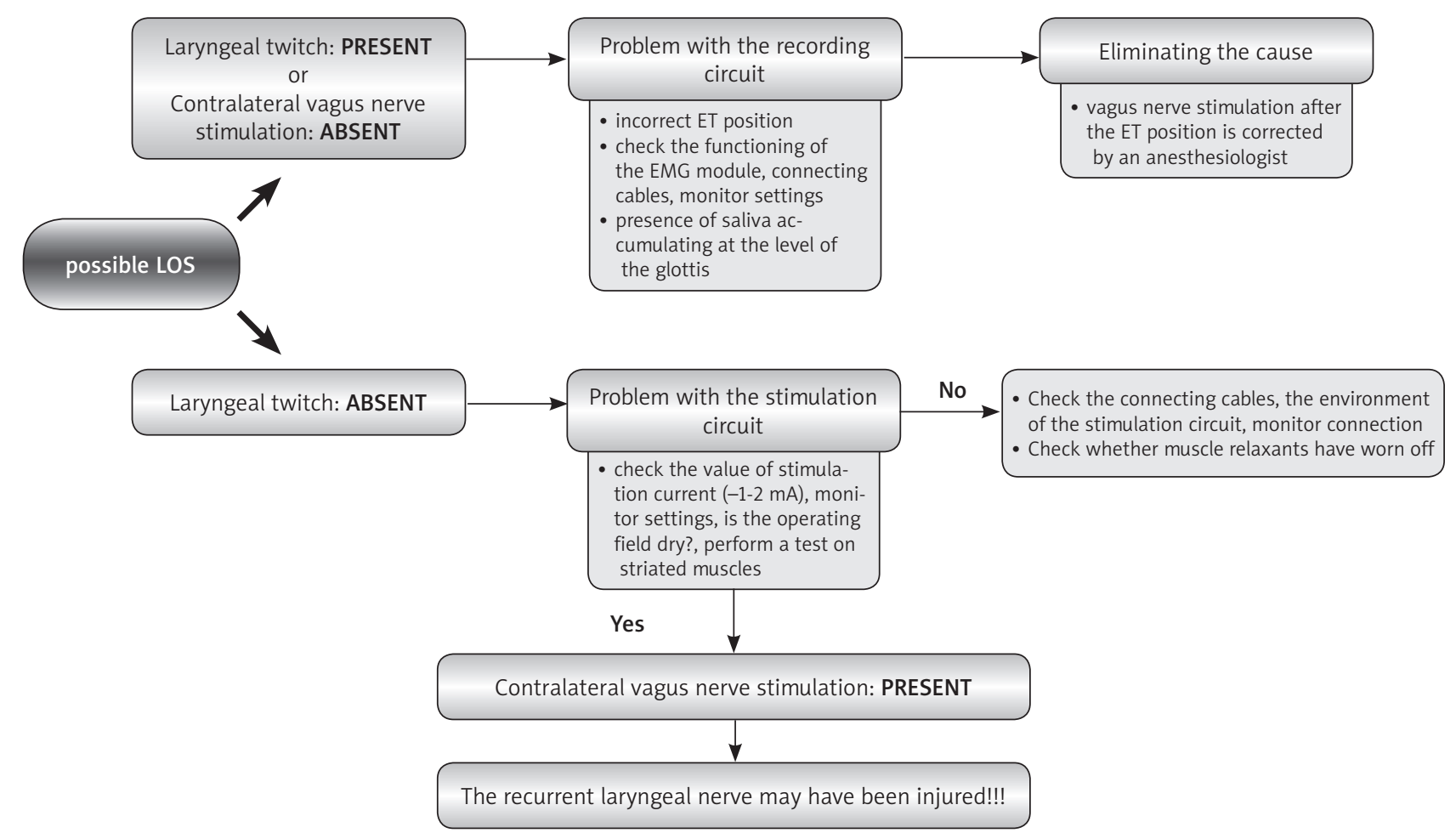

LOS definition:

1. The EMG reading is different from a previous reading which was considered to be correct

2. No response to stimulation or a reading with low peak-to-peak amplitude $(\leq 100 \mu \mathrm{V})$ despite correct values of stimulation current (1-2 mA) and dry operating field

3. No laryngeal twitch

\section{After confirming LOS:}

1. Map the damage in order to differentiate between type I (segmental) and type II (central) RLN injury

2. Decide whether to continue or to abort surgery on the opposite side

LOS - loss of signal

Fig. 3. Standards of conduct in the case of EMG loss of signal. Based on [2] 
tion is correct by stimulating the vagus nerve [2]. Endotracheal tube placement errors include rotation of the tube around its long axis. Rechecking monitor settings, with special attention to impedance values, may be very helpful in detecting endotracheal tube rotation.

Another problem that may occur during RLN neuromonitoring is the pooling of saliva at the level of the glottis. Intraoperative observations revealed increases of impedance values on recording electrodes during progressive salivary accumulation, which led to gradual loss of signal [2]. The use of a suction pump, as well as the administration of drying agents, may be helpful as well [2].

If no laryngeal twitch is present, the stimulation system should be examined (Figs. 1, 3). The stimulation electrode (probe) can be tested on a striated muscle, e.g. a strap muscle. If touching the muscle with an active probe causes it to twitch, it proves that the probe is working correctly and that neuromuscular blockade is not maintained [2]. When working with the stimulation probe, one has to remember that the frequency of the impulses it sends is $4 / \mathrm{s}$ [2]. The technique of working with the stimulation probe should be based on searching through the tissue with the tip of the probe, instead of irregular touching or "skipping" over the surface of the tissue. Since electrocoagulation, both mono- and bipolar, may generate disturbances, it is recommended to physically separate diathermy and IONM equipment [2]. The distance between them should be at least $3 \mathrm{~m}$ [2]. Some of the modern EMGs are capable of working within the environment of diathermy. IONM does not influence the function of harmonic scalpels and Ligasure devices.

Another step is to check the connection and technical condition of the cables connecting the stimulation probe (neurostimulator) with the monitor, as well as the fixation of the neutral electrode. It may be dislodged when the patient perspires [2]. If the signal is still missing after the entire stimulation system is checked, it is necessary to reconsider whether the stimulated anatomical structure is actually a nerve. It is least cumbersome to begin the verification with the vagus nerve, as it constitutes an easily identifiable anatomical structure. If no vagus nerve activation is revealed, it is recommended to confirm or exclude the presence of neuromuscular blockade associated with the activity of muscle relaxants (Fig. 3). If the attempts to stimulate the RLN and vagus nerve do not cause EMG activity, or a significant reduction of electromyographic activity is found, it is necessary to patiently reanalyze the EMG signal loss algorithm point by point (Fig. 3). If the electromyographic signal still remains unsatisfactory, the surgeon should then suspect nerve damage [2].

The loss of EMG signal can only be determined if the signal was previously achieved [2]. If a previously satisfactory EMG signal drops below $100 \mu \mathrm{V}$ despite the use of an adequate stimulation threshold, then LOS should be considered [2]. It is recommended to record the results of laryngeal twitch assessment and/or glottis observation along the previously noted EMG data [2]. If LOS is deter- mined, it is necessary to identify the site of damage and establish an optimal contralateral surgery strategy [2].

The surgeon should attempt to identify the injury site. The search should begin at the most distal part of the RLN (i.e. the laryngeal nerve entry site) and continue in the proximal direction. Identifying a neuropraxic segment of the nerve allows the surgeon to analyze the individual stages of the surgery and may potentially provide better understanding of the surgical maneuver that may have injured that specific segment (e.g. excessive traction, compression, clamping, or ligation) [10]. RLN injuries identified by means of neuromonitoring may be divided into two types [10]. The first type involves local RLN injury and is referred to as segmental damage. It is potentially possible to correct this lesion if it is associated with temporary clamping, or attempt to suture the segment if it was cut [10]. Retrograde mapping with a stimulation probe may demonstrate that the RLN is non-conductive in all segments (entire RLN and vagus nerve). This suggests global damage to the RLN, usually localized in the larynx. This type of damage is referred to as type 2 or central RLN damage [10]. In the case of central RLN damage, it should be assumed that the RLN function on the contralateral side is impaired as well, at least temporarily [10]. According to the INMSG, taking into consideration the patient's best interest and the possibility of bilateral paralysis, it is recommended to consider concurrent surgery on the other lobe of the thyroid in such cases [2]. In many situations, when postoperative laryngeal examination confirms transient neuropraxia, postponing the continuation of the procedure by several weeks may enable the restoration of nerve function on the contralateral side [5]. Thanks to the aforementioned algorithm, such complications as bilateral vocal cord paralysis or the necessity of performing tracheotomy may cease to pose problems in thyroid surgery [5]. It is, of course, necessary to perform surgery on the correctly functioning side of the nerve in the case of advanced neoplastic diseases. However, the awareness that this is the only functioning nerve is important both for the surgeon and the patient [5].

The end of IONM-assisted surgery should be preceded by the stimulation of the RLN and vagus nerve. On the basis of the stimulation results, the surgeon may attempt to make a prognosis concerning the postoperative function of the vocal cords [2]. In order for this prognosis to be correct in the highest percentage of cases possible, the operator should keep in mind the causes of false negative and false positive results of stimulation.

A false positive result occurs when no satisfactory EMG image is achieved after RLN and/or vagus stimulation at the end of surgery, but, despite that, vocal cord paralysis is not confirmed postoperatively [2]. The causes of such events include the following: various problems with equipment, blood or fascia surrounding the stimulated nerve segment, persistent neuromuscular blockade, and transient vocal cord paralysis. Large centers which utilize IONM frequently have experience with transient vocal cord paralysis subsiding before the end of surgery [10]. The pop- 
ularization of IONM will probably enable researchers to document a larger number of cases of transient vocal cord paralyses lasting seconds, minutes, days, or weeks, which are well known in clinical practice and have been described in the literature [10]. The sooner the postoperative glottic function examinations are performed, the more cases of hyperacute transient RLN neuropraxia are diagnosed [2].

A false negative result occurs when a satisfactory EMG reading from the RLN and/or vagus nerve is achieved, but vocal cord paralysis is diagnosed postoperatively [2]. According to Koester et al., a positive motor response may occur only when the continuity of the RLN-posterior thyroarytenoid muscle axis is at least partially maintained [11]. Partial denervation of the posterior thyroarytenoid muscle may allow for the occurrence of a motor reaction as a result of stimulation, but cannot provide a clinical guarantee of adequate muscle twitch strength [11]. The cause of this phenomenon is yet to be explained. The occurrence of vocal cord paralysis despite correct intraoperative test results is rare, but may be caused by the following [2]:

Distal stimulation with regard to the damaged nerve segment. This is the reason why vagus nerve stimulation should be performed at the end of surgery.

Nerve damage occurring after previous stimulation.

Delayed neuropraxia. There is a hypothesis that progressive edema may influence the intralaryngeal part of the RLN at the level of the cricoarytenoid joint. This phenomenon may also be caused by a vascular effect.

Posterior RLN branch injury. Neuromonitoring assesses only the vocal cord muscles, not the posterior cricoarytenoid muscle. In order to examine the function of this muscle, innervated by the posterior RLN branch, it would be necessary to use separate electrodes. Theoretically, it is possible that the RLN branch running to the posterior cricoarytenoid muscle may become injured. Despite that, RLN stimulation will provide a positive signal from the vocal cords, innervated by the anterior branch. Since the posterior cricoarytenoid muscle is the only muscle responsible for opening the glottis, its isolated injury may result in postoperative paresis or paralysis of the vocal cords $[12,13]$.

Dysfunction of the vocal cords may be associated with causes not resulting from the actions of the surgeon [2]. The endotracheal tube may cause injury, emphysema, and damage to the vocal folds, and result in voice change. Intubation may even result in displacement of the arytenoid cartilage [5]. Strap muscle damage or their denervation may also influence the patient's voice [5]. Damage to the paralaryngeal nerve plexus without any injury of the RLN or superior laryngeal nerve, as well as paralaryngeal scarring, may also impact the function and mobility of the larynx and, therefore, voice and swallowing [5].

On the basis of the scarce information found in the literature and the more up-to-date registers concerning the quality of thyroidectomy procedures, it is possible to conclude that performing solely visual examination after lobectomy enables the detection of just $10 \%$ of nerve injuries [5]. According to Randolph et al., acquiring an EMG signal through vagus nerve stimulation after lobectomy has a negative prognostic value of $99.6 \%$ [5].

\section{References}

1. Zagólski O, Stręk P. Porażenia nerwów zaopatrujących ruchowo krtań. Probl Laryngol Codz Prakt 2003; 34: 2-6.

2. Randolph GW, Dralle H; International Intraoperative Monitoring Study Group, Abdullah H, Barczynski M, Bellantone R, Brauckhoff M, Carnaille B, Cherenko S, Chiang FY, Dionigi G, Finck C, Hartl D, Kamani D, Lorenz K, Miccolli P, Mihai R, Miyauchi A, Orloff L, Perrier N, Poveda MD, Romanchishen A, Serpell J, Sitges-Serra A, Sloan T, Van Slycke S, Snyder S, Takami H, Volpi E, Woodson G. Electrophysiologic recurrent laryngeal nerve monitoring during thyroid and parathyroid surgery: international standards guideline statement. Laryngoscope 2011; 121 Suppl 1: S1-16.

3. Dionigi G, Bacuzzi A, Boni L, Rovera F, Dionigi R. What is the learning curve for intraoperative neuromonitoring in thyroid surgery? Int J Surg 2008; 6 Suppl 1: 7-12.

4. White WM, Randolph GW, Hartnick CJ, Cunningham MJ. Recurrent laryngeal nerve monitoring during thyroidectomy and related cervical procedures in the pediatric population. Arch Otolaryngol Head Neck Surg 2009; 135: 88-94.

5. Randolph GW. Anatomia chirurgiczna, śródoperacyjny neuromonitoring i operacyjne postępowanie $z$ nerwem krtaniowym wstecznym oraz nerwem krtaniowym górnym. In: Atlas technik chirurgicznych gruczołów dokrewnych. Duh QY, Clark OM, Kebebew E, Brzeziński J (eds.). Elsevier Urban \& Partner; Wrocław 2011; 79-104.

6. Dralle H, Sekulla C, Haerting J, Timmermann W, Neumann HJ, Kruse E, Grond S, Mühlig HP, Richter C, Voss J, Thomusch O, Lippert H, Gastinger I, Brauckhoff M, Gimm O. Risk factors of paralysis and functional outcome after recurrent laryngeal nerve monitoring in thyroid surgery. Surgery 2004; 136: $1310-1322$.

7. Grant CS. Anatomia chirurgiczna tarczycy, przytarczyc i nadnerczy. In: Chirurgia. Narządy wewnętrznego wydzielania. Fischer JE (ed.). Medipage, Warszawa 2011; 140-152.

8. Yap SJ, Morris RW, Pybus DA. Alterations in endotracheal tube position during general anaesthesia. Anaesthesia Intensive Care 1994; 22: 586-588.

9. Chiang FY, Lu IC, Kuo WR, Lee KW, Chang NC, Wu CW. The mechanism of recurrent laryngeal nerve injury during thyroid surgery - the application of intraoperative neuromonitoring. Surgery 2008; 143: 743-749.

10. Snyder SK, Lairmore TC, Hendricks JC, Roberts JW. Elucidating mechanisms of recurrent laryngeal nerve injury during thyroidectomy and parathyroidectomy. J Am Coll Surg 2008; 206: 123-130.

11. Koester $\mathrm{P}$, Wolf $\mathrm{M}$, Zorowka S. Neuromonitoring in thyroid surgery: the view of the laryngologist. Eur Surg 2003; 35: 246-249.

12. Rea L, Kahn A. Clinical evoked electromyography for current laryngeal nerve preservation: use of an endotracheal tube electrode in a postcricoid surface electrode. Laryngoscope 1998; 108: 1418-1420.

13. Marcus B, Edwards B, Yoo S, Byrne A, Gupta A, Kandrevas J, Bradford C, Chepeha DB, Teknos TN. Recurrent laryngeal nerve monitoring in thyroid and parathyroid surgery: the University of Michigan experience. Laryngoscope 2003; 113: 356-361.

14. Lu IC, Chu KS, Tsai CJ, Wu CW, Kuo WR, Chen HY, Lee KW, Chiang FY. Optimal depth of NIM EMG endotracheal tube for intraoperative neuromonitoring of the recurrent laryngeal nerve during thyroidectomy. World I Surg 2008; 32: 1935-1939.

15. Cherng $\mathrm{CH}$, Wong CS, Hsu CH, Ho ST. Airway length in adults: estimation of the optimal endotracheal tube length for orotracheal intubation. J Clin Anesth 2002; 14: 271-274. 